\title{
The identification of areas vulnerable to radiocaesium deposition in Hungary
}

\author{
S.M. Wright, N.M.J. Crout ${ }^{1}$, N.A. Beresford, A.L. Sanchez and B. Kanyar ${ }^{2}$ \\ Centre for Ecology and Hydrology, Merlewood, Windermere Road, \\ Grange-over-Sands, Cumbria LA11 6JU, U.K. \\ ${ }^{1}$ School of Life \& Environmental Science, University of Nottingham, Nottingham NG7 2RD, U.K.
}

\begin{abstract}
Radiocaesium is an important and persistent environmental contaminant that can be deposited following nuclear accidents. It became apparent after the Chernobyl accident that some regions were vulnerable to radiocaesium deposition. Prior identification of vulnerable areas using spatial models that incorporate variation in radiocaesium soil-to-plant transfer as a function of soil properties would allow post-accident management options to be prioritised and effectively implemented. In this paper, an assessment of the influence of different input soil property data sets for Hungary upon spatial model predictions of cow milk ${ }^{137} \mathrm{Cs}$ activity concentrations and the identification of vulnerable areas is presented. Although predictions of cow milk ${ }^{137} \mathrm{Cs}$ activity concentrations after Chernobyl made using the three input soil property data sets are all broadly similar and in reasonable agreement with national monitoring data, the identification of vulnerable areas is greatly influenced by the input soil property data set used. Our results suggest that using soil property databases derived from amalgamation of soil properties into broad soil categories will lead to vulnerable areas not being identified. The findings presented in this paper have important implications for the use of spatial models in the prediction of radiocaesium transfer, identification of vulnerable areas and management of contaminated areas.
\end{abstract}

\section{INTRODUCTION}

Radiocaesium is an important and persistent environmental contaminant that can be deposited following nuclear accidents as demonstrated by that at the Chernobyl nuclear power plant. Soil-to-plant transfer of radiocaesium, which determines ingestion doses received by populations in the mid- to long-term after an accidental release, is influenced by a number of soil properties (e.g. [1]). However, whilst models have been developed to estimate radiocaesium transfer to food products incorporating processes such as interception, weathering, resuspension, fixation and leaching in soils, root uptake and transfer to animals (e.g. [2,3]), variation in plant uptake as a function of soil properties has at best only been incorporated by simply varying transfer on the basis of broad soil categories (e.g. [4]). It became apparent after the Chernobyl accident that a number of regions were 'vulnerable' to radiocaesium deposition. Prior identification of vulnerable areas using spatial models that include variation in radiocaesium transfer due to different soil properties would allow post-accident management decisions to be prioritised and, in the event of an accident, more effectively implemented.

\subsection{The SAVE-IT software package}

Recently a user-friendly software system (SAVE-IT) has been developed to allow the mid- to long-term impacts of radiocaesium deposition in Western Europe to be quantified and vulnerable areas identified [5]. The system utilises a semi-mechanistic radiocaesium soil to plant transfer model developed and parameterised following experiments undertaken to quantify the uptake of radiocaesium over a wide range of soils types (see [6 and 7]). Four soil properties, \% clay, exchangeable $\mathrm{K}, \mathrm{pH}$ and \% organic C, readily available from existing soils databases, are used to predict radiocaesium transfer for seven 
representative agricultural crops (pasture grass, winter wheat, leafy vegetables, potato, root crops, maize silage and fruit). The activity concentration of nine animal food products (beef, pork, poultry, sheep and goat meat, eggs, and cow, sheep and goat milk) is predicted from the product of an equilibrium transter coefficient, an animal's daily dry matter intake and the predicted activity concentration in the feedsuff. Daily dry matter intakes of feed types (currently pasture, 'stored' grass (hay and silage), maize silage and cereal based concentrates) for each animal species are defined over the course of a season within six bi. monthly intervals (January-February, March-April, etc.). All feedstuffs are assumed to be derived from local sources and will therefore reflect local contamination levels predicted by the spatial model. For Western Europe, spatial databases of model input parameters including Chernobyl and global fallout ${ }^{137} \mathrm{Cs}$ deposition, soil properties, land use and agricultural production have been developed using geographical information systems and embedded in the software system using a raster data structure (i.e. the area of interest is subdivided into uniform grid cells) with a resolution of $5 \times 5 \mathrm{~km} \mathrm{[5].}$

Because spatial soils data were required for the whole of Western Europe it was necessary to develop input soil property data sets from generalised soil data with a coarse resolution. However, when being applied to a specific country or region it is possible to derive model input spatial databases from national data sets with a view to improving the reliability of model predictions [8]. In this paper we present an assessment of the different available input soil property data sets for Hungary on predictions of ${ }^{137} \mathrm{Cs}$ activity concentrations in cow milk and the identification of areas that may be vulnerable to radiocaesium deposition.

\section{DERIVATION OF INPUT SOIL PROPERTY DATA SETS FOR HUNGARY}

SAVE-IT was originally developed for the 15 EC countries and Norway. A spatial database of input sol properties was derived from the Soil Geographical Data Base of Europe (SGDBE; [9]) as it provided sufficient coverage, spatial resolution and consistency for the whole of Western Europe. For Hungaryit was hypothesised that using input data sets derived from national data would allow better estimates of radiocaesium transfer to be made than using data derived from European scales.

To examine the influence of different input soil property data sets upon model predictions, three sels of input soil properties for Hungary with a resolution of $5 \times 5 \mathrm{~km}$ were derived. The first (referred to as $S G D B E$ soil class) was derived from the SGDBE. The SGDBE provides spatial data on the distribution of 219 soil types from 23 major soil groups across Europe at a scale of 1:1 million and is accompanied by a data set of 588 typical soil profiles. Mean soil properties were calculated for those soil types mapped by the SGDBE within Hungary and a soil property data set derived by identifying the mean soil propertyat the centre of each $5 \times 5 \mathrm{~km}$ pixel. Spatial data on the distribution of 31 different soil types from 7 major soil groups within Hungary at a scale of 1:100 000 and a database of 1226 georeferenced measured sol] profiles was used to generate the second and third input soil property data sets. The second input soll property data set (referred to as Hungarian soil class) was generated by calculating mean soil propetty values for each of the 31 soil types by identifying the spatial coincidence of national soil profiles and sol types and selecting the mean soil property value at the centre of each $5 \times 5 \mathrm{~km}$ pixel. The good spatial coverage of the 1226 profiles in the Hungarian soil profile database allowed the third input soil property database (referred to as Hungarian kriged) to be derived using spatial interpolation. Semivariograms for each of the four soil properties were plotted and block kriging, using parameters describing spatid dependences derived from the semivariograms, used to estimate the mean soil property values within each $5 \times 5 \mathrm{~km}$ pixel.

The spatial pattern of soil properties varies between the three input soil property data sets; Figure I illustrates this for exchangeable $\mathrm{K}$. For the SGDBE soil class input data set, spatial variation in soll properties occurs as blocks with few soil types, whereas, for the Hungarian soil class input data set the finer resolution of the soil type spatial data leads to soil properties varying over smaller blocks, oftent the level of individual $5 \times 5 \mathrm{~km}$ pixels. The soil properties in the Hungarian kriged input data set exhibit smoothed variation as would be expected when using block kriging interpolation. When averaged over Hungary (Table 1) the three input soil property data sets generally appear to be comparable (i.e. the meal values are similar). The SGDBE soil class input data set exhibits greater ranges, especially maximum 
values, than the Hungarian soil class input data but this may be expected when deriving soil properties using soil profile data for the whole of Europe.

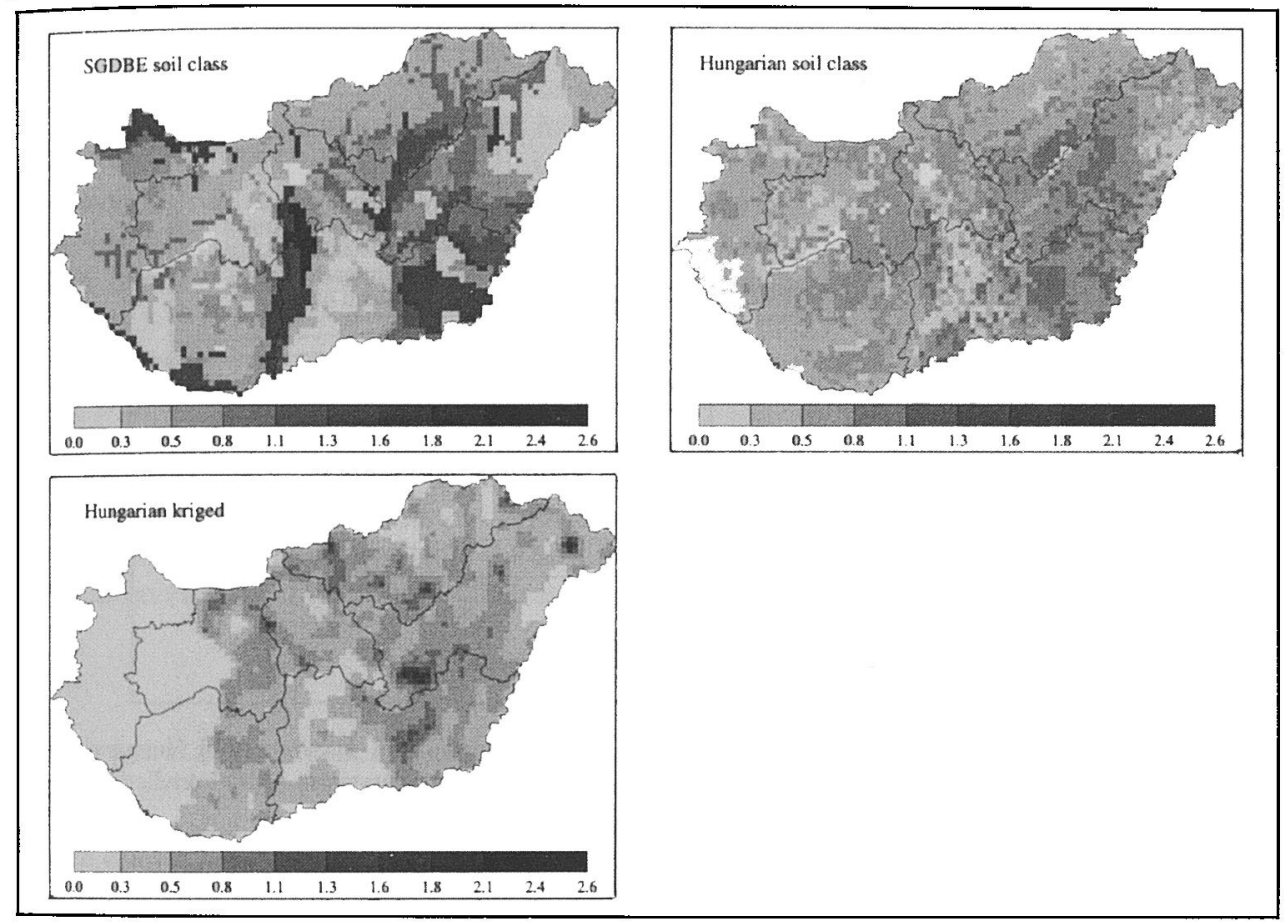

Figure 1: Comparison of exchangeable $\mathrm{K}$ as generated for the three input soil property data sets.

Table 1: Summary of three input soil property data sets used in this analysis.

\begin{tabular}{|l|c|c|c|c|c|c|c|c|}
\hline \multirow{2}{*}{ Dataset } & \multicolumn{9}{|c|}{ Soil property } \\
\cline { 2 - 10 } & \multicolumn{2}{|c|}{ \% clay } & \multicolumn{2}{c|}{ Exch. K (meq kg) } & \multicolumn{2}{c|}{$\mathrm{pH}$} & \multicolumn{2}{c|}{ \% organic C } \\
\cline { 2 - 10 } & Range & Mean & Range & Mean & Range & Mean & Range & Mean \\
\hline 1. SGDBE soil class & $6.0-68.0$ & 24.6 & $0.1-1.9$ & 0.6 & $4.8-8.5$ & 7.2 & $0.7-21.7$ & 2.5 \\
\hline 2. Hungarian soil class & $4.9-46.2$ & 23.0 & $0.03-1.0$ & 0.5 & $5.3-8.8$ & 7.0 & $0.5-3.2$ & 1.3 \\
\hline 3. Hungarian kriged & $2.6-49.3$ & 21.1 & $0.01-2.5$ & 0.4 & $5.4-7.9$ & 6.9 & $0.4-2.9$ & 1.1 \\
\hline
\end{tabular}

\section{POST-CHERNOBYL PREDICTIONS}

Predictions of ${ }^{137} \mathrm{Cs}$ activity concentrations in cow milk following the Chernobyl accident have been made using the three input soil property data sets and modified agricultural management regimes typical for the region. For Hungary, the spatial variation in total post-Chernobyl ${ }^{137} \mathrm{Cs}$ deposition was estimated from De Cort et al. [10]; deposition being assumed to occur on 1 May 1986. The spatial variation in ${ }^{137} \mathrm{Cs}$ transfer to cow milk was predicted with a transfer coefficient $\left(\mathrm{F}_{\mathrm{m}}\right)$ value of 0.008 day $\mathrm{kg}^{-1}$ and a pasture grass intake rate of $17 \mathrm{~kg} \mathrm{DW}_{\text {day }}{ }^{-1}$ [11]. Predicted cow milk ${ }^{137} \mathrm{Cs}$ activity concentrations made using the three input soil property data sets are compared to national monitoring data for Hungary in Figure 2.

Predictions made using the three input soil property data sets are all in general agreement with measured data, although there is a slight under prediction in the mid-term. The simplification in this assessment that all the animals diet is derived from fresh grass may contribute in part to this; in reality animals would have been fed conserved forage with comparatively higher ${ }^{137} \mathrm{Cs}$ activity concentrations over the winter of $1986 / 87$. In the long-term, mean predictions of ${ }^{137} \mathrm{Cs}$ activity concentrations in cow milk are in good agreement with measured data. However, there is a consistent difference between long- 
term predictions made using the three input soil property data sets in the order: Hungarian kriged > SGDBE soil class $>$ Hungarian soil class.

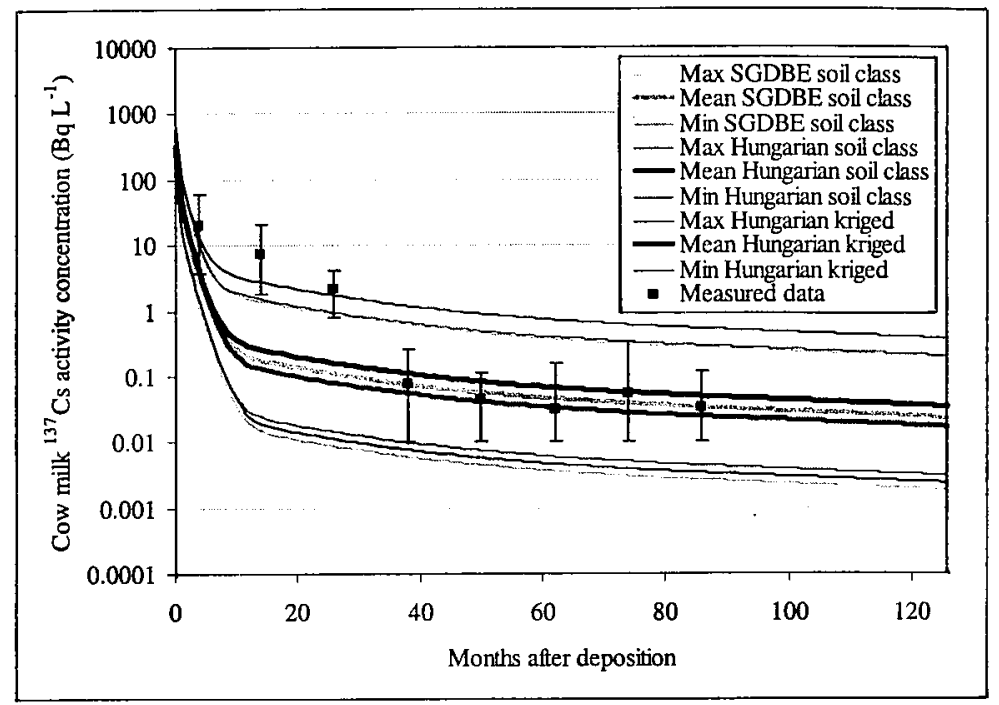

Figure 2: Predicted cow milk ${ }^{137} \mathrm{Cs}$ activity concentrations (minimum, mean and maximum) in Hungary following the Chernobyl accident made using the spatial model and the three input soil property data sets. Model predictions are compared to national monitoring data summarised (minimum, mean and maximum) for Hungary.

\section{PREDICTION OF VULNERABLE AREAS}

The spatial model and associated spatial databases of land cover and agricultural production allow the prediction of food product ${ }^{137} \mathrm{Cs}$ activity concentrations, fluxes and ingestion doses, all of which can be used to identify areas that may be vulnerable to radiocaesium deposition. Within this analysis, to examine the influence of input soil property data upon the identification of vulnerable areas, ${ }^{137} \mathrm{Cs}$ cow milk activity concentrations were predicted using an $F_{m}$ value of 0.008 day $\mathrm{kg}^{-1}$, a pasture grass intake rate of $17 \mathrm{~kg} \mathrm{day}^{-1}$, and assuming a uniform deposition of $10000 \mathrm{~Bq} \mathrm{~m}$ occurring on 1 January. Model predictions for the summer of the first and fifth years after deposition are shown in Figures 3 and 4.

Although the above prediction of mean ${ }^{137} \mathrm{Cs}$ activity concentrations in cow milk for Hungary showed broadly similar values for the three input soil data sets, the spatial pattern of milk contamination varies considerably depending upon input data set. Using the Hungarian kriged data set, areas of Western, Central and Southern Transdanubia are identified as being vulnerable to radiocaesium deposition, especially in the longer-term. These areas would not have been identified as being as vulnerable if predictions were made using the input data sets derived using either soil class information. It would appear that differences between the predicted cow milk ${ }^{137} \mathrm{Cs}$ activity concentrations made using the three input soil property data sets are due to low exchangeable $\mathrm{K}$ values in Western Hungary within the Hungarian kriged input soil property data set (compare Figure 1 with Figures 3 and 4).

Greater spatial variation in predicted cow milk ${ }^{137} \mathrm{Cs}$ activity concentrations were observed after 6 months using the Hungarian soil class data set compared with predictions using the SGDBE soil class input data set. However, in the longer-term, this is reversed with greater spatial variation in cow milk ${ }^{13} \mathrm{Cs}$ activity concentrations being predicted by the SGDBE soil class data set.

\section{DISCUSSION}

The differences between the spatial predictions made using the different input soil property data sets are sufficient as to have significant implications for post-accident management: the kriged soil property data 
set predicts cow milk ${ }^{137} \mathrm{Cs}$ activity concentrations in comparatively large areas of Western Hungary which are circa one order of magnitude greater than predicted by the other soil input data sets. Due to the lack of sufficient monitoring data, both spatially and temporally, it is difficult to identify which input soil property data set is making the most realistic predictions. However, the Hungarian kriged input soil property data set is derived from soil properties measured at specific locations, rather than soil properties averaged over broad soil types (i.e. we can have some confidence that these soil properties occur in a given area). This may suggest that deriving soil property databases by amalgamation into broad soil categories will lead to vulnerable areas not being identified. Whilst we cannot be definite in our conclusion, our findings have important implications for the use of spatial models in the prediction of radiocaesium transfer, identification of vulnerable areas and management of contaminated areas.

\section{Acknowledgements}

The SAVEC project was carried out under contract to the European Commission DGXII (ERB IC15CT98-0206), whose support is gratefully acknowledged. The authors would also like to thank the Centre of the Database of Soil Measurement and Information at the Central Station of Soil Protection and Plant Hygiene, Budapest for making available the soil profile database for Hungary and Sarjan Tandor of the National Food Investigation Institute, Budapest for providing national monitoring data.

\section{References}

[1] F.R. Livens, P.J. Loveland, Soil Use and Management 469 (1988).

[2] H. Müller and G. Pröhl, Hlth Phys. 64232 (1993).

[3] F.W. Whicker and T.B. Kirchner, Hlth Phys. 52717 (1987).

[4] M.T. Edley, Review of SPADE Soil-Plant-Animal Models, Report to UK Ministry of Agriculture, Fisheries and Food, ANS 2274-2 (1990).

[5] B.J. Howard, S.M. Wright, C.L. Barnett (Eds), Spatial Analysis of Vulnerable Ecosystems in Europe: Spatial and dynamic prediction of radiocaesium fluxes into European foods (SAVE). Final report to the Commission of the European Communities (1999).

[6] J.P. Absalom, S.D. Young, N.M.J. Crout, A.F. Nisbet, R.F.M. Woodman, E. Smolders, A.G. Gillett, Env. Sci. \& Tech. 331218 (1999).

[7] J.P. Absalom, S.D. Young, N.M.J. Crout, A. Sanchez, S.M. Wright, E. Smolders, A.F. Nisbet, A.G. Gillett, J. Environ. Radioact. 5231 (2001).

[8] A.G. Gillett, N.M.J Crout, J.P. Absalom, S.M. Wright, S.D. Young, B.J. Howard, C.L. Barnett, S.P. McGrath, N.A. Beresford, G. Voigt, Rad. Env. Biophys. (in press).

[9] European Soil Bureau (1999). The European Soil Data Base (version 1.0). Supplied on CD-ROM. European Soil Bureau, European Commission.

[10] M. De Cort, G. Dubois, Sh.D. Fridman, M.G. Germenchuk, Yu.A. Izrael, A. Janssens, A.R. Jones, G.N. Kelly, E.V. Kvasnikova, I.I. Matveenko, I.M. Nazarov, Yu.M. Pokumeiko, V.A. Sitak, E.D. Stukin, L.Ya. Tabachny, Yu.S. Tsaturov, S.I. Avdyushin, Atlas of caesium deposition on Europe after the Chernobyl accident. (Office for Official Publications of the European Communities, Luxembourg, 1998).

[11] International Atomic Energy Agency, Handbook of Parameter Values for the Prediction of Radionuclide Transfer in Temperate Environments. Technical Report Series No. 364 (International Atomic Energy Agency, Vienna, 1994). 

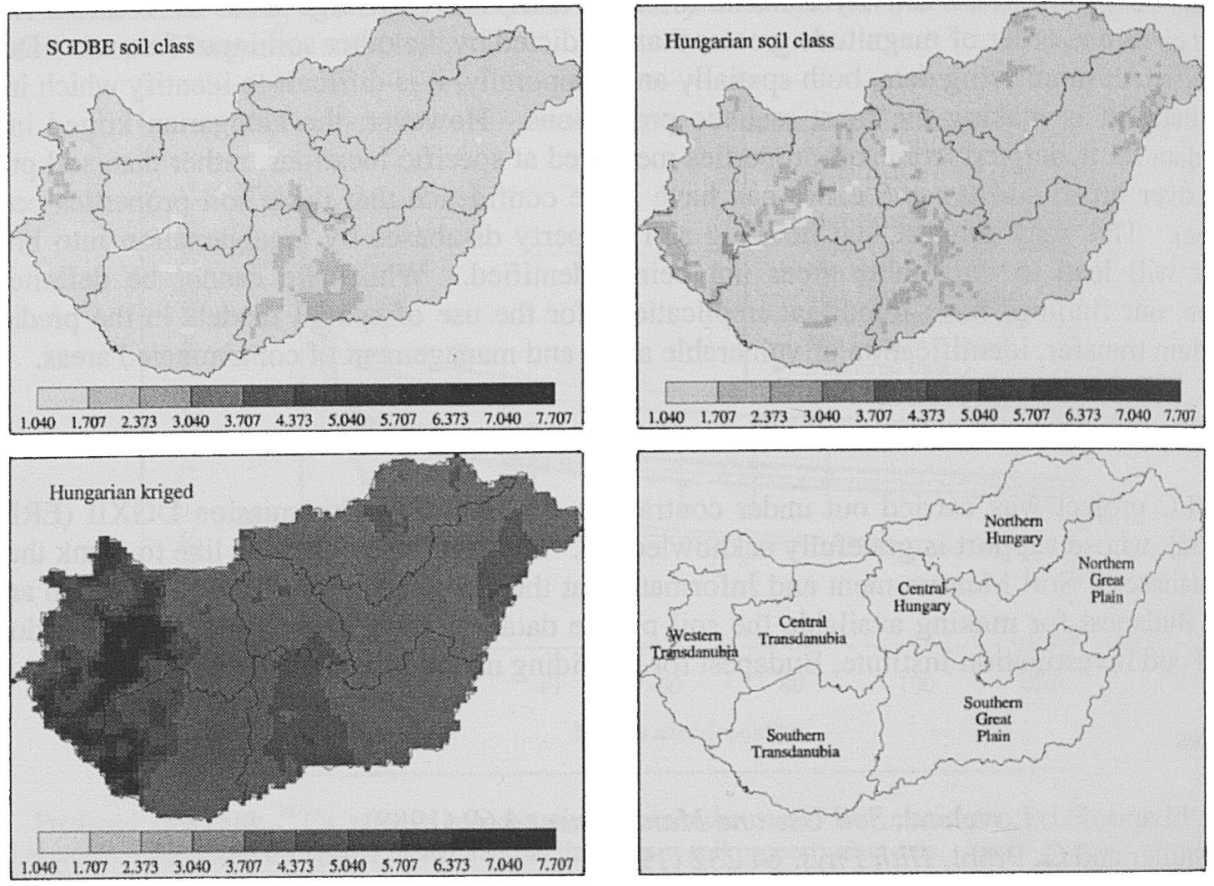

Figure 3: Spatial variation in predicted cow milk ${ }^{137} \mathrm{Cs}$ activity concentrations $\left(\mathrm{Bq} \mathrm{L} \mathrm{L}^{-1}\right)$ in Hungary 6 months after a uniform deposition of $10000 \mathrm{~Bq} \mathrm{~m}^{-2}$ occurring on 1 January using the three input soil property data sets. The main regions of Hungary are shown bottom right.

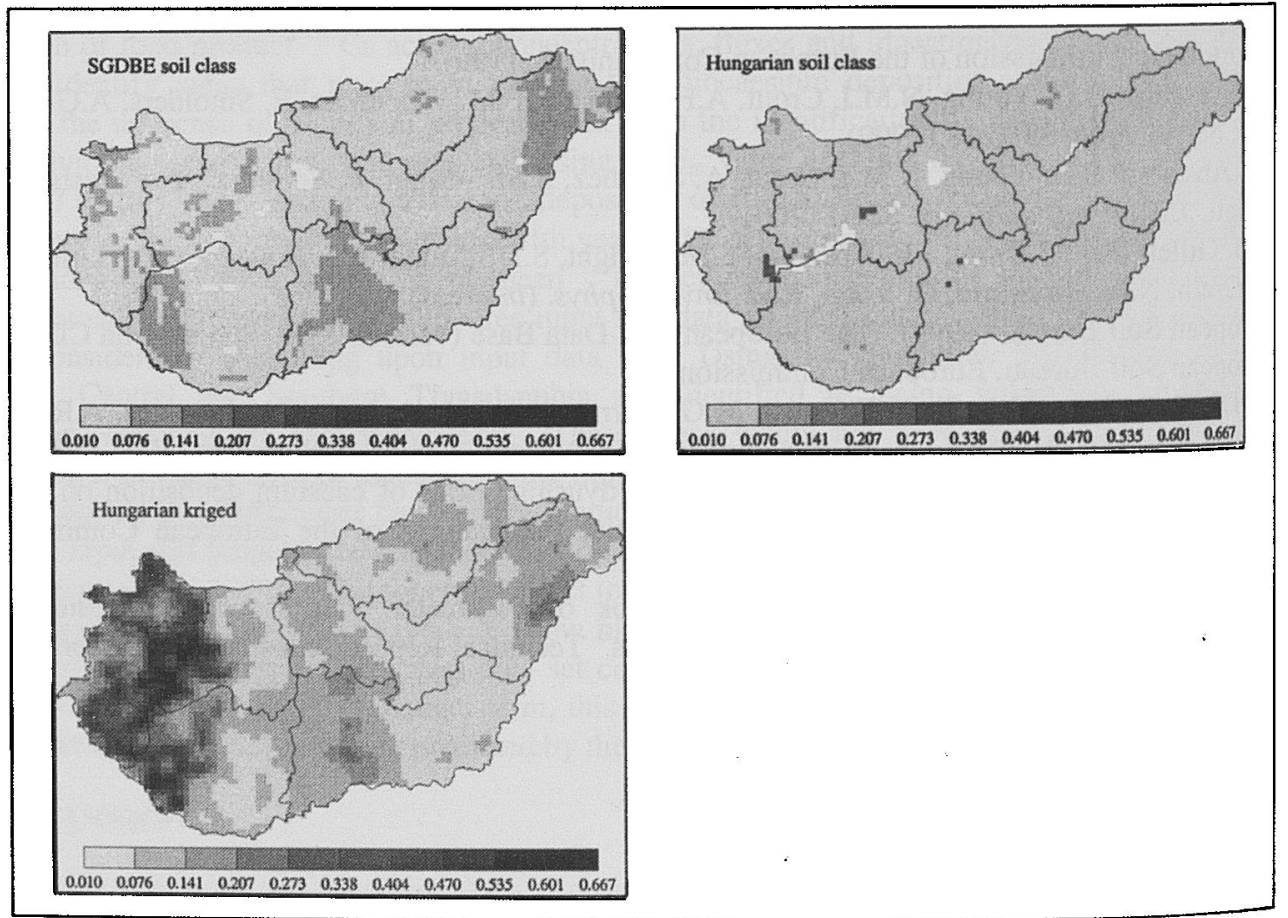

Figure 4: Spatial variation in predicted cow milk ${ }^{137} \mathrm{Cs}$ activity concentrations $\left(\mathrm{Bq} \mathrm{L}{ }^{-1}\right)$ in Hungary 66 months after a uniform deposition of $10000 \mathrm{~Bq} \mathrm{~m} \mathrm{~m}^{-2}$ occurring on 1 January using the three input soil property data sets. 